\title{
Visual cortical evoked potentials under conditions of apparent motion*
}

\author{
J. L. ANDREASSI. M. S. MAYZNER, M. STERN, and H. OKAMURA \\ New York Liniversity. Bronx. New York 10453
}

\begin{abstract}
The present study examined visual evoked potentials (VEPs) under three subjectively different stimulus conditions. two of which involved apparent motion. The hypotheses that the apparent motion conditions would result in smaller amplitude VEPs were rejected by data analyses. indicating very similar responses under all three conditions. It was suggested that nervous system mechanisms underlying the different perceptual experiences produced in this experiment must lie at some area in the brain other than those refiected in the iocations used in the present study.
\end{abstract}

In an earlier study. it was found that a stimulus pattern in which there appeared to be a flow of stimuli (five Xs) from left to right resulted in smaller amplitude visual evoked potentials (VEPs) than did a condition in which the stimuli appeared to have spaces between them (Andreassi, Mayzner. Beyda, \& Davidovics, 1971). A tentative hypothesis advanced the possibility that a broken, more complex visual pattern had greater. attention-getting value than a smooth-flowing configuration and, therefore, resulted in higher amplitude VEPs. Previous investigations have reported the effects of attention on evoked potential amplitudes (e.g., see Donchin \& Cohen, 1967; Groves \& Eason, 1969). To test this hypothesis and also to examine more closely the general question of the effects of apparent movement on the VEP, we designed three subjectively different stimulus conditions, using physically identical visual stimuli. Two of these conditions produced strong apparent motion, but in different directions, and one produced the appearance of a broken pattern of stimuli.

\section{METHOD}

\section{Subjects}

The Ss were six male faculty members and graduate students in the School of Engineering and Science at New York University, ranging in age from 21 to 28 years. None of the Ss had visual defects other than myopia (corrected to 20/20). All were practiced in visual perceptual tasks related to VEP studies.

\section{Apparatus and Procedure}

The Ss were. seated in an electrically shielded sound-attenuated room (IAC chamber) such that they were able to view a CRT display outside the room. Stimuli were presented on this CRT screen under control of a PDP-7 digital computer, in a manner described more fully later. All experimental sessions were conducted in darkness, with trials beginning after Ss had dark-adapted for $15 \mathrm{~min}$. Under these conditions, $\mathrm{S}$ saw only the stimuli on the screen for the duration of the experimental session.

*This research was supported by the Psychophysiology Program, Office of Naval Research, under ONR Contract No. N0014-67-A-0467-0009 and ONR Contract Authority No. NR 140-252 to the first two authors.
The EEG was recorded from $\mathrm{O}_{1}$ and $\mathrm{O}_{2}$ ("ten-twenty" system, Jasper, 1958), with Grass silver electrodes referenced to another electrode on S's left ear lobe. The S's left wrist was connected to "patient ground" on a Beckman RM dynograph via another electrode lead. Electrode resistance was measured at $5,000 \mathrm{ohms}$ or less for each $\mathrm{S}$. The $9806 \mathrm{~A}$ coupler of the dynograph was used to condition the EEG signal (bandpass set at 0.5 to $32.0 \mathrm{~Hz}$ ). The filtered and amplified signal was fed into a Mnemotron computer of average transients (CAT 1000). A "start" signal from the PDP-7 computer triggered the CAT to take EEG samples every $0.5 \mathrm{msec}$ for a $500-\mathrm{msec}$ duration following the presentation of each stimulus to $S$ and, upon termination of a given trial, the summated potential was printed out on a Hewlett-Packard X-Y plotter. Calibration was achieved by feeding a 40-microV $5-\mathrm{Hz}$ sine wave through the entire system, which resulted in an X-Y plotter vertical deflection of $24 \mathrm{~mm}$ for $5 \mathrm{micrcV}$. Samples of electro-oculograms (ECG) were recorded by the dynograph and averaged by the CAT to insure against eye-movement contamination of VEPs.

The experimental session consisted of three conditions of 150 presentations each. The stimuli displayed to Ss on the CRT were lines of 20 horizontal Xs: Each X was displayed sequentially with $\mathrm{ON}$ and $\mathrm{OFF}$ times of $5 \mathrm{msec}$, i.e., the first $\mathrm{X}$ was presented for $5 \mathrm{msec}$ (ON time) followed by a $5-\mathrm{msec}$ pause (OFF time), and then the next $X$ was displayed, etc., until all $20 \mathrm{Xs}$ were presented. The major difference between the three strings of Xs was the order in which they appeared. It was this order difference which produced the different perceptual experiences.

The display orders and locations of the 20 Xs were:

$$
\begin{array}{cc}
\text { Condition } & \text { Display Order-Locations }{ }^{1} \\
\text { A } & 2,4,6,8,10,12,14,16,18,1,20,19,17,15,13,11,9,7,5,3 \\
\text { B } & 18,16,14,12,10,8,6,4,2,1,3,5,7,9,11,13,15,17,15,20 \\
\text { C } & 10,18,8,15,6,17,7,3,2,1,20,11,19,5,16,9,14,4,12,13
\end{array}
$$

In the display orders used, the first $X$ always appeared in the center. Condition A consistently resulted in a subjective response which indicated that the "Xs converged toward the center from the right and left"; in Condition B, the response was that "Xs diverged from the center with a small gap in the middle" (both Conditions A and B produced an experience of "flowing motion"). However, Condition C resulted in responses which indicated that Ss saw "about 10 Xs with spaces in between" with no experience of motion. Therefore, our task was to determine whether these very dissimilar subjective experiences would be 
Table 1

Mean Amplitude ( $\mu v)$ for Major VEP Components Under Conditions $A$ (Converging Xs). B (Diverging Xs), and C (Broken Pattern of Xs) $(N=6)$

\begin{tabular}{|c|c|c|c|c|}
\hline \multirow{2}{*}{$\begin{array}{c}\text { Scalp } \\
\text { Location } \\
\end{array}$} & \multirow{2}{*}{$\begin{array}{c}\text { VIP } \\
\text { Component }\end{array}$} & \multicolumn{3}{|c|}{ Condition } \\
\hline & & A & В & $\mathrm{C}$ \\
\hline & Ni & 1.91 & 1.51 & 1.55 \\
\hline $\mathrm{O}_{1}$ & P1 & 2.41 & 2.46 & 2.57 \\
\hline lLeft & $\times 2$ & 5.47 & 5.01 & 4.88 \\
\hline \multirow[t]{2}{*}{ Hemisphere) } & $\mathrm{P} 2$ & 7.00 & 6.77 & 6.84 \\
\hline & $\times 3$ & 4.44 & 4.58 & 4.38 \\
\hline & $N 1$ & 1.64 & 1.54 & 1.64 \\
\hline $\mathrm{O}_{2}$ & Pl & 2.35 & 2.78 & 2.62 \\
\hline (Right & $\mathrm{N2}$ & 5.27 & 5.13 & 4.86 \\
\hline \multirow[t]{2}{*}{ Hemisphere) } & $\mathrm{P} 2$ & 6.93 & 6.93 & 6.96 \\
\hline & N3 & 3.42 & 5.68 & 4.10 \\
\hline
\end{tabular}

correlated with different V'LPs.

Each experimental session consisted of a number of practice trials for each condition. during which subjective reports of perceptual experience were recorded. Each condition consisted of 150 presentations and each was presented twice. counterbalanced among $\mathrm{Ss}$ by a Latin-square design. The $\mathrm{Ss}$ rested about $1 \mathrm{~min}$ between conditions. The $\mathrm{S}$ was instructed to concentrate on each presentation. count each one, and say "150" when this number was reached. Thus, there was a total of 900 stimulus presentations for each $\mathrm{S}$. He was also asked to fixate upon a small (1/8-in.-diam) dim red light located $1 / 2$ in. above the center $\mathrm{X}$. The $\mathrm{S}$ was asked not to blink his eyes during the presentation of stimuli. There was a $1-\mathrm{sec}$ interval between each stimulus presentation.

Since $S$ viewed the $1 / 2$-in.-high Xs from inside the IAC chamber at a distance of 45 in. the vertical dimension of a single $X$ produced a visual angle of $39 \mathrm{~min}$ at the eye. The intensity of each character was the same, $.130 \mathrm{~mL}$, as measured by a Gamma Scientific photometer. from inside the IAC chamber to the CRT outside, for a steady-state X. The CAT was triggered by the PDP-7 simultaneously with the presentation of the first $\mathrm{X}$ in the horizontal array.

The hypotheses for this experiment were: (1) Condition C would result in higher amplitude VEP components than Condition $B$, since $C$ presents the more complex, broken pattern: (2) Condition $B$ would produce higher amplitude components than Condition A, since B is slightly more complex than A because of the slight apparent gap: (3) there would be no latency differences of VEP components under the three conditions.

\section{RESULTS AND DISCUSSION}

The mean amplitudes (microvolts) and latencies (milliseconds) were computed for each of the six Ss from the primary X-Y tracings. The $\mathrm{N} 1$ components were considered to be the first negative dip in the plot. which occurred $50 \mathrm{msec}$ after the stimulus. The amplitude of the $\mathrm{N} 1$ component was measured as the vertical distance from the X-Y trace baseline to the trough of the first depression. The P1 component was measured as the vertical distance from the $X-Y$ trace baseline to the trough of the first depression. The P1 component was measured as the vertical distance from $\mathrm{N} 1$ to the peak of the first positive component, while N2 was measured as the vertical distance from the peak of $\mathrm{P} 1$ to the trough of the second major depression. and so on for P2 and N3. Latencies (or time after stimulus presentation) were measured to the midpoints of each positive and negative peak. If the "peak" was flat and appeared more as a plateau, the midpoint of the plateau was taken as the latency measurement.

The mean amplitudes for the various VEP components for each condition, across the six Ss are shown in Table 1 for $\mathrm{O}_{1}$ and $\mathrm{O}_{2}$. These values were tested for statistical significance by the $t$ test for correlated data. and no significant differences were shown between any of the comparisons (A vs B; $A$ vs $C$ : or $B$ vs $C$ ) for the major N2, P2 VEP components. A one-tailed criterion for significance was used at $5 \mathrm{df}$ at the .05 level of significance.

The mean latencies for the various VEP components for each condition, across the six Ss, are shown in Table 2 for $\mathrm{O}_{1}$ and $\mathrm{O}_{2}$. The same comparisons were analyzed by t test for correlated data, and none were found to be statistically significant for the one-tailed criterion at $5 \mathrm{df}$ at the .05 level.

The amplitude and latency data are both presented in Fig. 1. The averaged values for latency and amplitude are plotted as a smoothed curve which reflects the way in which the amplitudes and latencies of the raw VEP traces were actually measured. Thus, for the $\mathrm{O}_{1}$ curve, for example, the $\mathrm{N} 1$ component is the first negative dip in the VEP after $50 \mathrm{msec}$ (approximately $2 \mathrm{microV}$ in magnitude), reflecting the averaged latency and amplitude values for the six Ss. The averaged value of a VEP component was depicted only if it appeared in at least $50 \%$ of the total number of traces across Ss. This is because there are occasions when a particular component, e.g., N1 may not appear in a trace. The averaged and smoothed curves thus obtained reveal similar VEPs for Ss under the three stimulus conditions. for both $\mathrm{O}_{1}$ and $\mathrm{O}_{2}$.

Figure 2 shows the superimposed traces for one of the Ss (M.S.) under the three conditions, and it can be seen that the traces differ very little in amplitude, latency. or pattern for Conditions $\mathrm{A}, \mathrm{B}$, and $\mathrm{C}$ within both $\mathrm{O}_{1}$ and $\mathrm{O}_{2}$. There seems to be a slightly larger amplitude

Table 2

Mean Latency (Msec) for Major VEP Components Under Conditions A (Converging Xs), B (Diverging Xs), and $C$ (Broken Pattern) $(N=6)$

\begin{tabular}{|c|c|c|c|c|}
\hline \multirow{2}{*}{$\begin{array}{c}\text { Scalp } \\
\text { Location }\end{array}$} & \multirow{2}{*}{$\begin{array}{c}\text { VEP } \\
\text { Component }\end{array}$} & \multicolumn{2}{|c|}{ Condition } & \multirow[b]{2}{*}{$C$} \\
\hline & & A & B & \\
\hline $\begin{array}{c}\mathrm{O}_{1} \\
\text { (Left } \\
\text { Hemisphere) }\end{array}$ & $\begin{array}{l}\text { N1 } \\
\text { P1 } \\
\text { N2 } \\
\text { P2 } \\
\text { N3 }\end{array}$ & $\begin{array}{r}83 \\
122 \\
187 \\
287 \\
326\end{array}$ & $\begin{array}{r}74 \\
138 \\
190 \\
266 \\
319\end{array}$ & $\begin{array}{r}78 \\
140 \\
185 \\
266 \\
353\end{array}$ \\
\hline $\begin{array}{c}\mathrm{O}_{2} \\
\text { (Right } \\
\text { Hemisphere) }\end{array}$ & $\begin{array}{l}\text { N1 } \\
\text { P1 } \\
\text { N2 } \\
\text { P2 } \\
\text { N3 }\end{array}$ & $\begin{array}{r}78 \\
123 \\
183 \\
283 \\
315\end{array}$ & $\begin{array}{r}82 \\
136 \\
184 \\
267 \\
316\end{array}$ & $\begin{array}{r}75 \\
137 \\
180 \\
263 \\
355\end{array}$ \\
\hline
\end{tabular}


difference between $\mathrm{O}_{1}$ and $\mathrm{O}_{2}$ for M.S.. but $t$ tests showed no differences between these two locations for amplitude or latency measures when the data from the six Ss were used. A two-tailed criterion at $5 \mathrm{df}$ was used for the correlated $t$ tests. at the .05 level.

Our hypotheses that VEP amplitudes would be greater under Condition $C$ than under Condition $B$ and greater for Condition B than for Condition A because of complexity-attentional factors were not supported by the obtained data. The observed lack of latency differences under the three conditions was in line with our expectations. It is truly surprising that such strongly different subjective perceptual experiences did not result in different VEPs. Apparentli: the corticai mechanisms which produced the VEPs in both right and left occipital areas responded in a similar manner to the different stimulus conditions, even though the S's perceptual experience was very different. The nervous sytem mechanisms underlying the different perceptual experiences produced in this experiment may lie at some area in the brain other than the areas reflected in $\mathrm{O}_{1}$ and $\mathrm{O}_{2}$ activity. In a previous study (Andreassi et al, 1971). it was found that VEPs in a situation where two of five Xs were perceptually blanked were no different than the VEPs when Ss reported seeing all stimuli, indicating a physiological response to blanked stimuli although there was no perceptual recognition. Both the previous study and the present one suggest that perhaps areas of the nervous system other than the occipital cortex are
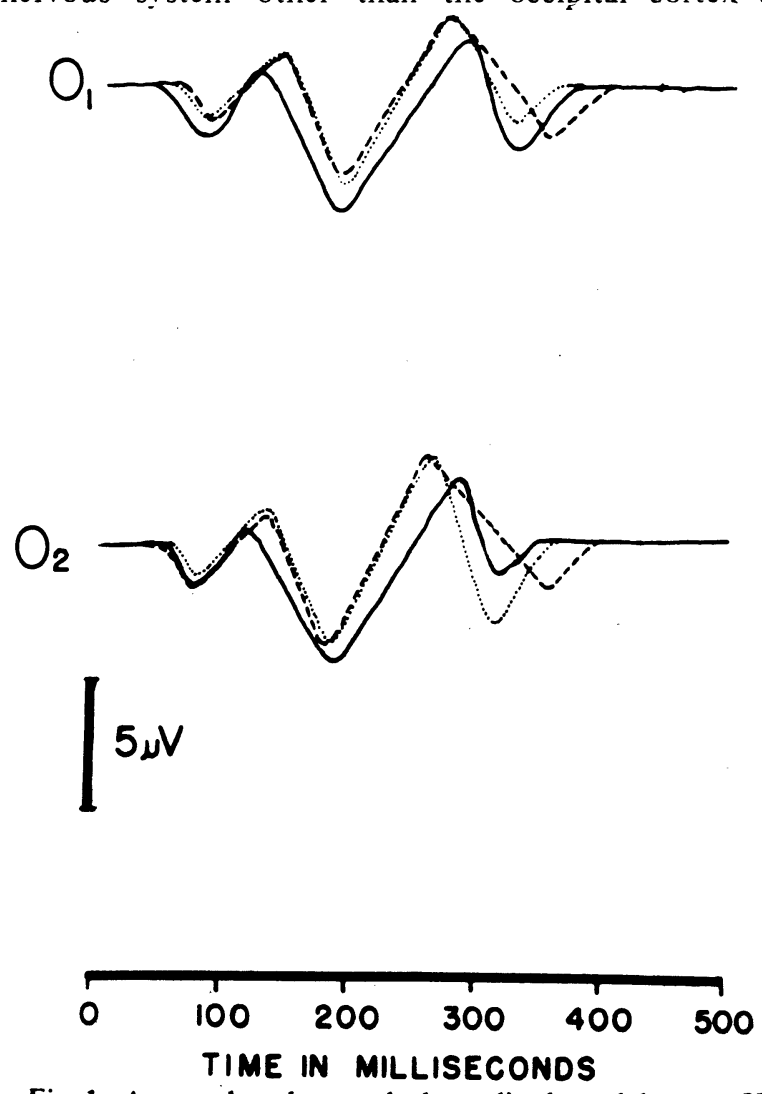

Fig. 1. Averaged and smoothed amplitude and latency VEP curve across six Ss under Conditions $A(-----)$, B $(\cdots \cdots)$, and $C(\cdots) \cdot$. Negativity is downward.

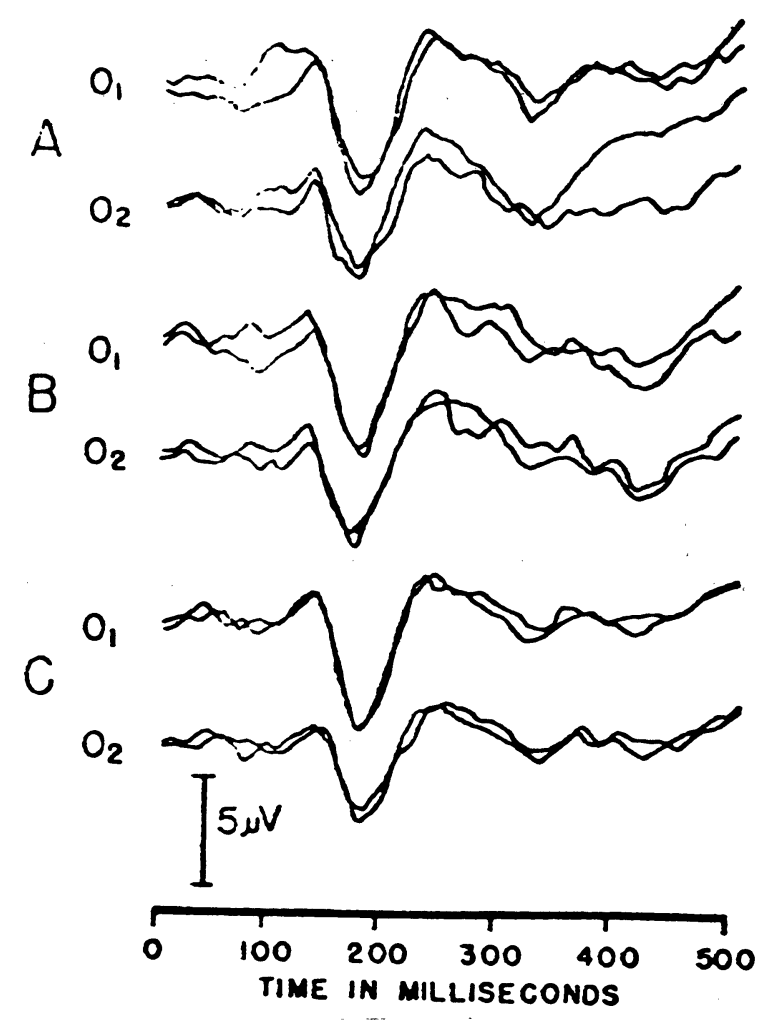

Fig. 2. VEPs of one $S$ (M.S.) under Conditions A (converging $\mathrm{Xs}$ ), B (diverging Xs), and C (broken pattern of Xs). Negativity is downward.

involved in mediating differences in the types of visual perceptual experience we have examined. However, we will continue to study VEPs to other types of dynamic visual displays in an effort to determine the generality of our findings.

\section{REFERENCES}

Andreassi. J. L., Mayzner, M. S., Beyda, D. B., \& Davidovics, S. Visual cortical evoked potentials under conditions of sequential blanking. Perception \& Psychophysics, 1971, 10, 164-168.

Jasper, H. H. Report of the committee on methods of examination in electroencephalography. Electroencephalography \& Clinical Neurophysiology. 1958, 10, 370-375.

Donchin, E., \& Cohen, L. Averaged evoked potentials and intramodality selective attention. Electroencephalography \& Clinical Neurophysiology, 1967, 22, 537-546.

Groves, P. M., \& Eason, R. G. Effects of attention and activation on the visual evoked cortical potential and reaction time. Psychophysiology, 1969, 5, 394-398.

\section{NOTE}

1. Display order refers to the sequence in which each $X$ appears. Thus, the X designated " 1 " appears first, " 2 " appears second, etc. Location refers to the relative position of each $X$ on the CRT display. Thus, for example, the first X (1) appears at the center of the screen under all three conditions.

(Received for publication July 28, 1972: revision received September 13. 1972.) 